\title{
АНАЛИЗ ПОДХОДОВ К ОЦЕНКЕ КОНКУРЕНТОСПОСОБНОСТИ РЕГИОНАЛЬНОГО ТУРИЗМА В РОССИИ
}

АНнотАция. В настоящее время в Российской Федерации наблюдается активное развитие сфер въездного и внутреннего туризма, представляющих большой интерес для национальной экономики с точки зрения сохранения и преумножения капитала государства. В этой связи для регионов РФ особенно острый характер приобретают проблемы конкуренции за туристский поток и объективной оценки собственной конкурентоспособности с целью выявления в ней сильных и слабых сторон и определения векторов развития сферы туризма. В статье выявляются составляющие понятия «конкурентоспособность» применительно к региональному туризму; автором дается определение данного понятия. Анализируются существующие подходы к оценке конкурентоспособности туризма в отечественной и зарубежной практике, выявляются их недостатки и достоинства с позиции практического использования для регионов России; приводятся блок-схемы рассматриваемых моделей. В работе обобщаются имеющиеся знания о факторах конкурентоспособности в сфере туризма. Рассматриваются существующие методы количественного измерения элементов в различных методиках оценки конкурентоспособности туризма.

кЛЮчЕВЫЕ СЛОВА. Региональный рынок туристских услуг; конкурентоспособность; методика оценки конкурентоспособности регионального туризма.

ИНФОРМАЦИЯ О СТАТЬЕ. Дата поступления 4 мая 2017 г.; дата принятия к печати 19 мая 2017 г.; дата онлайн-размещения 21 июня 2017 г.

M. Yu. Lassi

Baikal State University,

Irkutsk, Russian Federation

\section{ANALYSIS OF APPROACHES TO ASSESSING COMPETITIVENESS OF REGIONAL TOURISM IN RUSSIA}

\begin{abstract}
Now in the Russian Federation active development of the spheres of entrance and internal tourism which are of great interest to national economy from the point of view of preservation and enhancement of the capital of the state is observed. In this regard for regions of the Russian Federation especially acuity is gained by problems of the competition for a tourist stream and an objective assessment of own competitiveness for the purpose of identification in her strong and weaknesses and definition of vectors of development of the sphere of tourism. In article the making concepts "competitiveness» in relation to regional tourism come to light; the author gives definition of this concept. The existing approaches to an assessment of competitiveness of tourism in domestic and foreign practice are analyzed, their shortcomings and advantages from a position of practical use for regions of Russia come to light; flowcharts of the considered models are provided. In work the available knowledge of competitiveness factors in the sphere of tourism is generalized. The existing methods of quantitative measurement of elements in various techniques of an assessment of competitiveness of tourism are considered.
\end{abstract}

KEYWORDS. Regional market of tourist services; competitiveness; technique of an assessment of competitiveness of regional tourism.

ARTICLE INFO. Received May 4, 2017; accepted May 19, 2017; available online June 21, 2017.

(C) М. Ю. Ласси, 2017

\section{Baikal Research Journal}


Введение. Туристская индустрия на сегодняшний день является одной из наиболее перспективных и динамично развивающихся отраслей мировой экономики. При этом особую значимость для экономики любого государства имеет развитие въездного туризма как источника дополнительного капитала на территории государства и внутреннего туризма, обеспечивающего обращение доходов населения внутри страны.

Российская Федерация, с этой точки зрения, также не является исключением, и в течение нескольких последних лет ежегодно демонстрирует стабильный рост въездного ${ }^{1}$ и внутреннего ${ }^{2}$ туризма, составляя серьезную конкуренцию признанным странам-лидерам в данном экономическом сегменте и повышая градус конкурентной борьбы между собственными туристскими компаниями и регионами, как результат геополитической обстановки в мире 2014-2015 гг. Так, девальвация курса рубля по отношению к иностранной валюте, введение запрета для россиян на посещение ряда популярных заграничных туристских направлений и международные экономические санкции сделали более доступным для иностранцев отдых в России и, в свою очередь, ограничили покупательную способность наших соотечественников на заграничные туры.

В этой связи особенно актуальным представляется изучение вопроса конкурентоспособности региональных туристских рынков РФ. Поскольку именно уровень конкурентоспособности регионального туризма во многом определяет успешность и перспективность развития туристских компаний, сосредоточенных на территории региона, и самого региона по отношению к другим туристским субъектам государства и мира; указывает на наличие определенных проблем в отрасли и позволяет выявлять пути их решения.

Исходя из изложенного, первоочередной задачей для любого регионального туристского рынка должен стать выбор оптимальной методики оценки собственной конкурентоспособности для получения объективных и всесторонних результатов оценки.

Современное состояние и перспективы развития сферы туризма в России определили необходимость проведения анализа существующих подходов к оценке конкурентоспособности регионального туризма среди отечественных и зарубежных авторов, с целью выявления положительного опыта и возможностей его применения для повышения объективности оценки конкурентоспособности региональных рынков туристских услуг Российской Федерации.

Постановка проблемы. Проблема заключается в выборе наиболее рациональной методики оценки конкурентоспособности регионального туризма в условиях России с целью выявления угроз и возможностей для сферы въездного и внутреннего туризма на региональном уровне и определения вектора их дальнейшего развития в масштабах региона и страны.

Методика исследования. Информация для данной работы была получена на основании изучения внешних источников данных: пресс-релизы Международной туристской организации (ЮНВТО), специализированная литература, Интернет, веб-сайты федеральных и муниципальных органов власти, статистические сборники, веб-сайты российских и зарубежных туроператоров по внутреннему туризму, веб-сайты, специализирующиеся на изучении общественного мнения, относящегося к сфере туризма и т. д.

1 Въездной туризм в России показал беспрецедентный рост. URL: http://news24today.info/ vezdnoy-turizm-v-rossii-pokazal-bespretsedentnyy-rost.html.

${ }^{2}$ В России растет внутренний туризм. URL: http://kavnews.ru/turizm/v-rossii-rastet-vnutrenniieturizm.html.

\section{Baikal Research Journal}

электронный научный журнал Байкальского государственного университета 
Степень разработанности проблемы. Феномен «конкурентоспособность» в аспекте туризма рассматривается в работах отечественных и зарубежных авторов - Э. Б. Адельсеитовой и Л. Н. Джемилевой [1, с. 10-13], М. Н. Дмитриева, М. Н. Забаевой и Е. Н. Малыгиной [2], М. Мескона [3, с. 251], С. Г. Нейздойминова [4, с. 78-83], Р. А. Фатхутдинова [5] и др.

В работах перечисленных авторов имеются различные трактовки положений, характеризующих понятие «конкурентоспособность» применительно к сфере туризма, что позволяет сформулировать следующие основные положения, присущие данному понятию (табл. 1).

Таблица 1

Анализ положений, характеризующих понятие "конкурентоспособность", применительно к сфере туризма

\begin{tabular}{|l|l|}
\hline \multicolumn{1}{|c|}{ Автор } & \multicolumn{1}{|c|}{ Положение } \\
\hline М. Мескон & $\begin{array}{l}\text { Конкурентоспособность определяет возможность и динамику приспосо- } \\
\text { бления объекта к условиям рыночной конкуренции }\end{array}$ \\
\hline $\begin{array}{l}\text { Э. Б. Адельсеитова, } \\
\text { Л. Н. Джемилева }\end{array}$ & $\begin{array}{l}\text { Конкурентоспособность выражает отличия развития данной фирмы } \\
\text { от развития конкурентных фирм по степени удовлетворения потребно- } \\
\text { стей людей }\end{array}$ \\
\hline С. Г. Нездойминов & $\begin{array}{l}\text { Конкурентоспособность - это способность туристского продукта, произ- } \\
\text { водимого объектом, одновременно отвечать требованиям и его потреби- } \\
\text { телей и его производителей }\end{array}$ \\
\hline $\begin{array}{l}\text { Конкурентоспособность - это способность объекта удерживать высокий } \\
\text { конкурентный статус на туристском рынке в течение длительного периода }\end{array}$ \\
\hline $\begin{array}{l}\text { М. Н. Д. Змитриев, } \\
\text { Е. Н. Мабаева, }\end{array}$ & $\begin{array}{l}\text { Конкурентоспособность выражает отличия развития данной организа- } \\
\text { ции от развития организаций-конкурентов по степени удовлетворения } \\
\text { потребностей туристов и по эффективности бизнеса }\end{array}$ \\
\hline Р. А. Фатхутдинов & $\begin{array}{l}\text { Конкуренция возникает между территориальными образованиями } \\
\text { за туристский поток в настоящее время и в будущей перспективе } \\
\text { (т. е. за устойчивый туристский поток*) }\end{array}$ \\
\hline
\end{tabular}

* Примечание автора.

На основании данных положений, конкурентоспособность регионального туризма может быть определена как понятие, отражающее способность региона эффективно управлять своим туристско-рекреационным потенциалом в условиях рыночной конкуренции и отвечать требованиям, как потребителей, так и производителей туристского продукта, с целью обеспечения устойчивого потока туристов на подконтрольной территории в сравнении с аналогичными регионами на национальном и мировом туристских рынках.

При этом конкурентоспособность регионального туризма может быть качественно измерена и количественно оценена что позволяет «ранжировать» регионы в зависимости от ее значения.

На сегодняшний день единой методики оценки конкурентоспособности регионального туризма не разработано. В работах отечественных и зарубежных авторов [6-8] присутствует достаточно большое количество дифференцированных подходов к данному вопросу (как на национальном, так и на региональном уровне), включающих в себя различные элементы оценки, методы измерения и способы представления результатов. Как представляется, некоторые из них могут быть практически использованы для оценки регионального туризма в России. Однако определить целесообразность применения на региональном уровне той или иной методики оценки конкурентоспособности туризма и выбрать из них наиболее оптимальную, объективно отражающую ситуацию в отрасли, невозможно без проведения комплексного анализа всех наиболее известных методик, применяемых отечественными и зарубежными авторами в своих исследованиях.

\section{Baikal Research Journal}


Изучение литературы, посвященной данной тематике, свидетельствует, что ранее подобный анализ исследователями не проводился. Между тем, как отмечалось ранее, проблема выбора оптимальной методики оценки регионального туризма играет ключевую роль для получения объективных результатов оценки и разработки эффективных мер воздействия с целью дальнейшего развития сферы туризма на региональном и национальном уровнях.

Изложенное выше позволяет сформулировать следующую гипотезу исследования: является ли возможным и целесообразным практическое применение существующих подходов отечественных и зарубежных авторов к оценке конкурентоспособности туризма на уровне регионального туризма Российской Федерации?

Процесс изучения проблемы. Самой известной методикой оценки конкурентоспособности туризма на уровне отдельных государств является индекс конкурентоспособности туризма (Tourism competitiveness index - TCI), разработанный в 2007 г. Всемирным экономическим форумом (World Economic Forum). Данный индекс рассчитывается на основании 14 элементов, разделенных на три основные группы:

1. Регуляторы нормативно-правовой базы, оказывающие влияние на сферу туристских услуг на конкретной территории.

Бизнес среда и инфраструктура, обусловливающие процесс и порядок функционирования объектов сферы туризма.

3. Человеческие, природные и культурные ресурсы характеризующие уровень образования и квалификации работников туристской сферы, уникальность туристских ресурсов, сосредоточенных на территории, а также взаимоотношения между туристами и местными жителями [8, с. 162].

В табл. 2 представлены элементы, образующие Индекс конкурентоспособности национального туризма.

Таблица 2

Элементы, образующие индекс конкурентоспособности национального туризма

\begin{tabular}{|c|c|}
\hline Группа индикаторов & Элементы \\
\hline Нормативно-правовая база & $\begin{array}{l}\text { 1. Политические правила. } \\
\text { 2. Устойчивость окружающей среды. } \\
\text { 3. Охрана и безопасность. } \\
\text { 4. Гигиена и здоровье. } \\
\text { 5. Приоритетность сферы путешествий и туризма }\end{array}$ \\
\hline $\begin{array}{l}\text { Бизнес среда и } \\
\text { инфраструктура }\end{array}$ & $\begin{array}{l}\text { 1. Инфраструктура воздушного транспорта. } \\
\text { 2. Инфраструктура наземного транспорта. } \\
\text { 3. Туристская инфраструктура. } \\
\text { 4. Информационно-коммуникационная инфраструктура. } \\
\text { 5. Ценовая конкурентоспособность в туризме и путешестиях }\end{array}$ \\
\hline $\begin{array}{l}\text { Человеческие, природные и } \\
\text { культурные ресурсы }\end{array}$ & $\begin{array}{l}\text { 1. Человеческие ресурсы. } \\
\text { 2. Привлекательность туризма и путешествий. } \\
\text { 3. Природные ресурсы. } \\
\text { 4. Культурные ресурсы }\end{array}$ \\
\hline
\end{tabular}

Составлено по: [8].

Каждый из перечисленных 14 элементов, в свою очередь, должен быть представлен конкретными составляющими оценки, отражающими уровень и специфику конкурентоспособности исследуемого туристского рынка. Однако в литературе на сегодняшний день нет единого перечня данных составляющих ни для оценки национального туристского рынка, ни для оценки туристского рынка на региональном уровне. Разными авторами предлагаются различные составляющие оценки [6;8]. В качестве метода их количественного измерения исследователями

\section{Baikal Research Journal}


предлагаются интервьюирование и экспертный опрос с последующим выведением усредненного значения для каждой из составляющих [6; 8], что позволяет с наибольшей точностью выявлять сильные и слабые стороны в конкурентоспособности туристского объекта.

В настоящее время в литературных источниках встречается достаточно большое количество модификаций индекса конкурентоспособности туризма, созданных для оценки туризма на уровне отдельных регионов.

Так, Н. В. Шабалиной, на основании ТСI, была разработана собственная методика оценки конкурентоспособности региональных туристских рынков - индекс развития туризма. Индекс развития туризма - это интегральное понятие, характеризующее совокупность туристско-рекреационного потенциала региона, включая социально-экономические условия, и активности регионов в сфере развития туризма [9] (табл. 3).

Таблица 3

Составляющие индекса развития туризма

\begin{tabular}{|c|c|}
\hline Группа индикаторов & Индикаторы \\
\hline $\begin{array}{l}\text { Индикаторы турист- } \\
\text { ско-рекреационного по- } \\
\text { тенциала региона РФ }\end{array}$ & $\begin{array}{l}\text { 1. Природный потенциал региона. } \\
\text { 2. Культурно-исторический потенциал региона }\end{array}$ \\
\hline $\begin{array}{l}\text { Индикаторы социаль- } \\
\text { но-экономического разви- } \\
\text { тия региона РФ }\end{array}$ & $\begin{array}{l}\text { 1. Туристско-рекреационные потребности человека. } \\
\text { 2. Уровень жизни и здоровья населения. } \\
\text { 3. Инвестиционная привлекательность территории. } \\
\text { 4. Нормативно-правовое обеспечение туристской деятельности. } \\
\text { 5. Уровень информатизации общества. } \\
\text { 6. Качество окружающей среды. } \\
\text { 7. Инновативность предприятий региона }\end{array}$ \\
\hline $\begin{array}{l}\text { Индикаторы активности } \\
\text { туристско-рекреационной } \\
\text { деятельности в регионе } \\
\text { РФ }\end{array}$ & $\begin{array}{l}\text { 1. Доступность туристско-рекреационных услуг потребителю. } \\
\text { 2. Геополитическая стабильность и социальная безопасность. } \\
\text { 3. Атмосфера гостеприимства. } \\
\text { 4. Экономические механизмы стимулирования развития туризма. } \\
\text { 5. Предпринимательская активность населения. } \\
\text { 6. Институциональная активность (экспертная оценка). } \\
\text { 7. Кадровое обеспечение туристской деятельности. } \\
\text { 8. Динамика развития индустрии туризма }\end{array}$ \\
\hline
\end{tabular}

Источник: [9].

Для непосредственной количественной и качественной оценки указанных индикаторов автором предлагаются социологический опрос региональных специалистов индустрии туризма с расчетом усредненного значения результатов и кластерный анализ.

Следует отметить, что в практике оценки региональной конкурентоспособности достаточно часто имеют место аналитические или экспертные методики. Так, еще одним подобным примером служат работы У. Н. Воеводиной [10] и С. А. Туменовой [11]. Данные авторы в своих исследованиях опираются на концепцию национального ромба Майкла Портера в тандеме с последующим экспертным анализом, что позволяет составить комплексную оценку конкурентоспособности исследуемого регионального рынка туризма.

Согласно С. А. Туменовой, уровень конкурентоспособности регионального туризма в каждый конкретный момент времени определяется совместным действием ряда факторов внешней и внутренней среды. Подход к оценке данных факторов в целом и возможности воздействия региональных органов власти на ее составляющие можно сформулировать, опираясь на концепцию конкурентоспособности, предложенную М. Портером, и исследовать конкурентные позиции регионального

\section{Baikal Research Journal}

электронный научный журнал Байкальского государственного университета 
туристского рынка по четырем взаимосвязанным направлениям (детерминантам), образующим «конкурентный ромб» [11] (рис. 1).

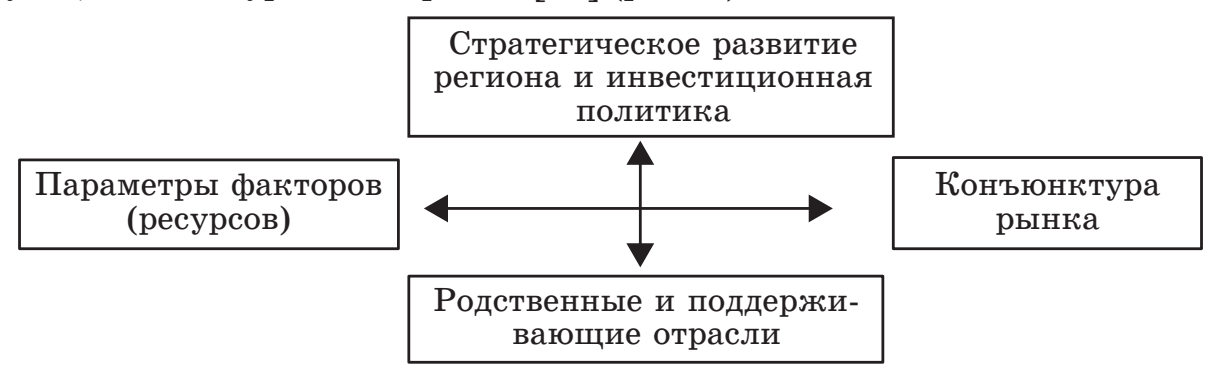

Рис. 1. Детерлинанты конкурентного преилущества

(Источник: [11, с. 28])

Оценка стратегического развития региона и инвестиционной политики подразумевает оценку организаций и управления туризмом в регионе, эффективность стратегического управления, оценку концепций, программ, стратегий развития в области туризма и смежных отраслях, уровень развития отдельных видов туризма, эффективность инвестиционной политики, деятельность общественных объединений сферы туризма.

Оценка факторов (ресурсов) - анализ степени обеспеченности сферы туризма туристско-рекреационными ресурсами, туристской инфраструктурой, трудовыми инвестиционными ресурсами.

Оценка конъюнктуры рынка - оценка показателей, характеризующих размер, потенциал спроса и предложения в туризме, сегментацию рынка, объем оказания платных услуг населению, ограничений со стороны внешней среды.

Оценка родственных и поддерживающих отраслей - уровень развития вспомогательных отраслей и сопутствующей инфраструктуры, качество услуг, предоставляемых этими отраслями [11, с. 28-30].

Каждая из перечисленных детерминант содержит в себе конкретные элементы оценки (табл. 4).

\section{Перечень приленяемых элементов оценки детерлинант конкурентного преилущества регионального туризла}

Таблица 4

\begin{tabular}{|c|c|}
\hline Детерминанта & Элементы оценки \\
\hline $\begin{array}{l}\text { Стратегическое } \\
\text { развитие региона } \\
\text { и инвестиционная } \\
\text { политика }\end{array}$ & $\begin{array}{l}\text { 1. Поддержка сферы туризма на государственном уровне. } \\
\text { 2. Система стратегического управления и государственного регулирования. } \\
\text { 3. Эффективность инвестиционной политики. } \\
\text { 4. Наличие и деятельность общественных объединений в сфере туризма }\end{array}$ \\
\hline $\begin{array}{l}\text { Параметры факто- } \\
\text { ров (ресурсов) }\end{array}$ & $\begin{array}{l}\text { 1. Туристско-рекреационные ресурсы. } \\
\text { 2. Туристская инфраструктура. } \\
\text { 3. Трудовой потенциал. } \\
\text { 4. Инвестиционная привлекательность и привлечение инвестиций. } \\
\text { 5. Межрегиональные связи }\end{array}$ \\
\hline $\begin{array}{l}\text { Конъюнктура } \\
\text { рынка }\end{array}$ & $\begin{array}{l}\text { 1. Объем и сегментация туристского потока. } \\
\text { 2. Общий объем платных услуг населению. } \\
\text { 3. Существенные макроэкономические ограничения. }\end{array}$ \\
\hline $\begin{array}{l}\text { Родственные и } \\
\text { поддерживающие } \\
\text { отрасли }\end{array}$ & $\begin{array}{l}\text { 1. Средства размещения. } \\
\text { 2. Сфера общественного питания. } \\
\text { 3. Транспортная инфраструктура. } \\
\text { 4. Сфера торговли и бытового обслуживания. } \\
\text { 5. Дополнительные платные услуги }\end{array}$ \\
\hline
\end{tabular}

Источник: [10].

\section{Baikal Research Journal}


Содержание табл. 4 свидетельствует, что большинство элементов имеют функциональную задачу освещения общей социально-экономической ситуации в регионе и государстве, а также всесторонней оценки отрасли туризма. Также необходимо отметить, что в модели не используются какие-либо специфичные элементы оценки, которые могут быть присущи конкретной туристской дестинации и, как следствие, нарушать универсальный характер данной методики оценки.

Для измерения отобранных элементов У. Н. Воеводина предлагает использование метода экспертной оценки.

Еще одной зарубежной методикой оценки конкурентоспособности регионального туризма, в основу которой положен экспертный метод оценивания элементов, является модель Вобера. Ее отличительной особенностью является наглядность получаемых результатов оценки, представляемых в виде картосхем, с возможностью последующего сравнения конкурентоспособности одного туристского рынка с другим. Так, Р. Наркъюнин в своей работе применяет модель Вобера для сравнения конкурентоспособности регионов Восточная Окстейтиджа в Литве и Оребро в Швеции (рис. 2).

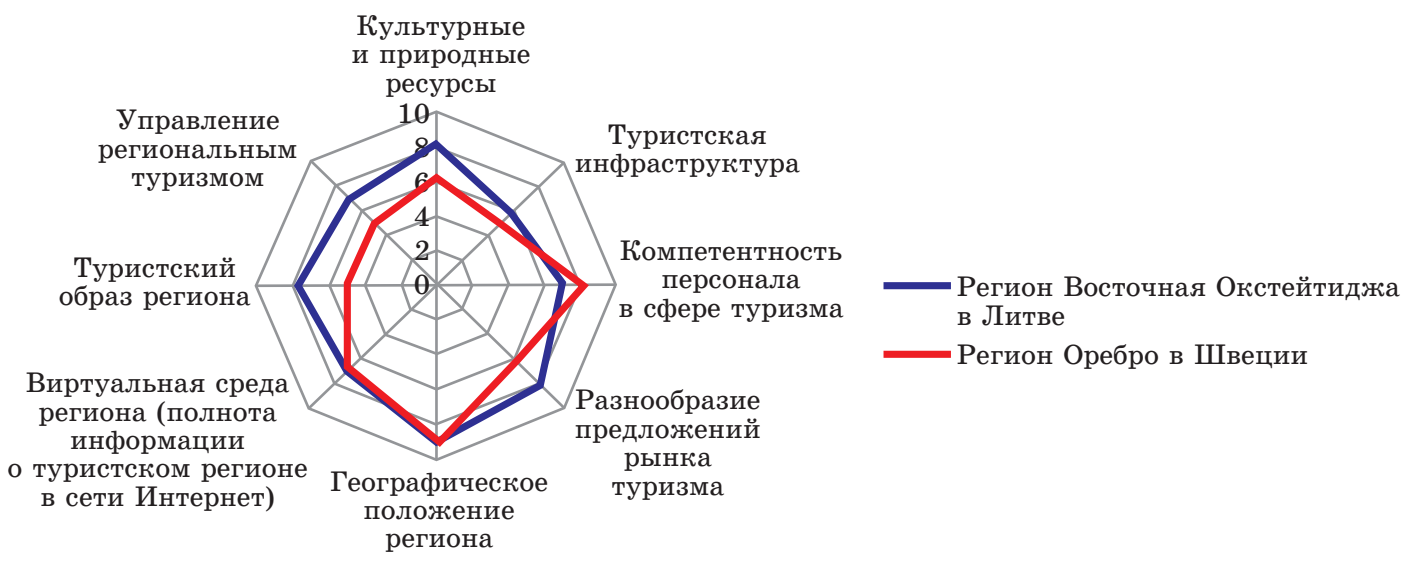

Рис. 2. Модель Вобера: сравнение конкурентоспособности регионов

Восточная Окстейтиджа в Литве и Оребро в Швеции (Источник: $[12$, р. 6])

Основными группами элементов конкурентоспособности в модели Вобера являются:

- туристские ресурсы;

- туристская инфраструктура;

- компетентность персонала в сфере туризма;

- разнообразие предложений рынка туризма;

- географическое положение региона;

- виртуальная среда региона (полнота информации о туристском регионе в сети Интернет).

Однако отсутствие в литературных источниках перечня конкретных элементов оценки, раскрывающих содержание каждой из представленных групп, позволяет использовать данную методику лишь в виде модифицированных моделей, в которых авторами предлагается собственный перечень элементов оценки, что, несомненно, может вызвать ряд проблем и концептуальных расхождений в результатах, а также самих методах количественного измерения элементов. Например, Р. Наркъюнин в своей работе предлагает производить количественную оценку элементов в модели Вобера по 10-бальной системе в ходе интервью со

\section{Baikal Research Journal}


специалистами сферы туризма, где 1 балл - очень плохое состояние элемента, 10 баллов - превосходное состояние [12, p. 4-8].

Следует отметить, что не все авторы придерживаются мнения о целесообразности и практической возможности использования экспертных методов в оценке конкурентоспособности регионального туризма $[13 ; 14]$, несмотря на широко распространенную практику их применения.

Так, по мнению Ф. Диманше, экспертные методы оценки не лишены такого существенного недостатка, как ограниченность выборки социологического опроса. То есть в методах экспертной оценки существует ограничение по количеству туристских направлений и респондентов, которые могут быть включены в исследование, что, в свою очередь, накладывает ограничение на количество элементов оценки и количество туристских рынков, которые следует оценить [14]. Кроме того в экспертных методах оценки зачастую имеет место субъективный характер оценки. Этот фактор, в свою очередь, во многом зависит от ограниченности числа респондентов, принимающих участие в исследовании, поскольку даже одно субъективное или непрофессиональное мнение способно оказать существенное влияние на объективность результатов оценки конкурентоспособности регионального туризма.

В этой связи, некоторыми исследователями [13] в противовес использованию экспертных методов предлагается использование математических методов для количественного измерения результатов оценки. Так, наиболее распространенной методикой оценки конкурентоспособности региональных туристских рынков, в основу которой положены математические методы, является Монитор конкурентоспособности (Competitiveness Monitor).

Непосредственно в сегменте регионального туризма Монитор конкурентоспособности нашел свое отражение в работах Р. Триснавати [15] и А. Л. Флита [13]. Модифицируя ряд элементов первоначальной модели, и вводя дополнительные элементы, А. Л. Флитом была разработана универсальная модель оценки конкурентоспособности индустрии туризма в региональном аспекте, элементы которой были представлены общепринятыми статистическими показателями (рис. 3).

Несмотря на отсутствие данных об апробации Монитора конкурентоспособности в рамках регионального туризма России, универсальный характер данной методологии позволяет ее использовать для оценки конкурентоспособности любых региональных туристских рынков. Это объясняется тем, что в данной модели в качестве показателей оценки используются наиболее общие статистические данные, единые для разных регионов Российской Федерации и других государств и зачастую доступные для большинства пользователей Интернета.

Обсуждение. Большинство из рассмотренных в работе методик оценки конкурентоспособности регионального туризма предусматривают использование экспертных методов измерения элементов конкурентоспособности путем опроса и интервьюирования специалистов индустрии туризма, а также самих туристов. На наш взгляд, целесообразность применения данных методов может быть подвергнута сомнению, ввиду наличия достаточно субъективного характера оценки. Кроме того нельзя исключать и такой существенный недостаток экспертных методов оценки, как ограниченность выборки при проведении социологических опросов. Как представляется, измерение показателей конкурентоспособности регионального туризма с помощью математических методов способно дать более точные, объективные и наглядные результаты оценки.

В этой связи, на наш взгляд, наиболее пригодной методикой оценки конкурентоспособности регионального туризма является Монитор конкурентоспособности. Данная модель помимо математических методов измерения элементов, предусматривает и наиболее объективный источник информации о состоянии конкуренто-

\section{Baikal Research Journal}


способности регионального туризма - статистические данные, что в совокупности практически полностью исключает параметр субъективности оценки. Еще одним неоспоримым преимуществом Монитора конкурентоспособности является доступность и экономичность проведения исследований на основании статистических данных, публикуемых государственными органами статистики - большинство статистической информации представлено в открытом доступе в сети Интернет. При этом показатели статистики, используемые для оценки регионального туризма, едины в различных регионах РФ и совпадают с большинством показателей, используемых зарубежными органами статистики национального и регионального мониторинга, что открывает исследователям новые возможности для сравнения конкурентоспособности отечественного и зарубежного регионального туризма.

\begin{tabular}{|c|c|}
\hline \multicolumn{2}{|c|}{ Монитор конкурентоспособности туристской дестинации } \\
\hline $\begin{array}{c}\text { Ценовая } \\
\text { конкурентоспособность } \\
\text { (РСI) } \\
\end{array}$ & $\begin{array}{l}\text { Цены гостиниц и ресторанов. } \\
\text { Цены на туристские товары и услуги } \\
\text { (сувениры и т. д.) } \\
\text { Паритет покупательной способности }\end{array}$ \\
\hline $\begin{array}{c}\text { Развитие } \\
\text { инфраструктуры (IDI) }\end{array}$ & \begin{tabular}{|l} 
Индекс развития дорог. \\
Развитие железнодорожной сети. \\
Количество авиакомпаний. \\
Развитие телекоммуникационных систем. \\
Наличие санитарной инфраструктуры. \\
Качество питьевой воды
\end{tabular} \\
\hline $\begin{array}{c}\text { Состояние } \\
\text { окружающей среды } \\
\text { (EERI) }\end{array}$ & $\begin{array}{l}\text { Плотность населения. } \\
\text { Уровень СО2. } \\
\text { Количество ратифицированных соглашений } \\
\text { в области экологической политики }\end{array}$ \\
\hline $\begin{array}{c}\text { Уровень технического } \\
\text { прогресса (TAI) }\end{array}$ & \begin{tabular}{|l} 
Интернет индекс. \\
Телефонный индекс. \\
Мобильный индекс. \\
Высокотехнологическое производство \\
\end{tabular} \\
\hline $\begin{array}{l}\text { Человеческие ресурсы } \\
\text { (HRI) }\end{array}$ & $\begin{array}{l}\text { Ожидаемая продолжительность жизни. } \\
\text { Уровень образования. } \\
\text { Процент неграмотных. } \\
\text { Половозрастной состав. } \\
\text { Уровень подготовки и развития навыков } \\
\end{array}$ \\
\hline $\begin{array}{c}\text { Открытость рынка } \\
\text { (MOI) }\end{array}$ & \begin{tabular}{|l} 
Визовый индекс. \\
Степень открытости туризма и торговли. \\
Налоги на международную торговлю
\end{tabular} \\
\hline $\begin{array}{c}\text { Уровень туристского } \\
\text { участия (НTI) }\end{array}$ & \begin{tabular}{|l} 
Спрос на туристские услуги. \\
Уровень потребления туристских услуг. \\
Экспорт туристских услуг. \\
Импорт туристских услуг. \\
Количество личных и деловых поездок. \\
Количество прибывших (убывших) \\
\end{tabular} \\
\hline $\begin{array}{c}\text { Социальное развитие } \\
\text { (SDI) } \\
\end{array}$ & $\begin{array}{l}\text { Индекс социального развития. } \\
\text { Интернет-кафе. } \\
\text { WI-FI сети }\end{array}$ \\
\hline
\end{tabular}

Рис. 3. Структура монитора конкурентоспособности

для оценки регионального туризма

(Составлено по: [13, с. 33])

\section{Baikal Research Journal}


Однако необходимо отметить, что монитор конкурентоспособности также может быть дополнен рядом существенных элементов, с наибольшей точностью отражающих уровень конкурентоспособности исследуемого туристского рынка, как например, частота повторных посещений региона туристами, которая характеризует степень удовлетворенности туристами отдыхом в данном регионе и готовность посетить его вновь, а также другими элементами, в совокупности оказывающими мощное влияние на потенциальных туристов при выборе того или иного региона назначения.

Таким образом, результаты проведенного анализа свидетельствуют о возможности и целесообразности практического применения некоторых существующих подходов к оценке конкурентоспособности туризма, основанных на количественных методах измерения элементов («Монитор конкурентоспособности»), на уровне регионального туризма Российской Федерации.

Заключение. Изучение отечественных и зарубежных подходов к оценке конкурентоспособности регионального туризма показало, что большинство известных методик оценки конкурентоспособности регионального туризма могут быть практически использованы в условиях Российской Федерации, как в исходном виде, так и в виде модифицированных моделей

Между тем рассмотренные модели имеют достаточно дифференцированный характер используемых показателей и подходов к количественному измерению показателей, что может приводить и к различным результатам оценки конкурентоспособности регионального туризма в Российской Федерации. Так, на наш взгляд, для получения объективных и своевременных результатов оценки конкурентоспособности регионального туризма в Российской Федерации необходимо разработать новую рациональную методику, которую могут единообразно использовать все регионы.

Важность решения данного вопроса во многом обусловливается необходимостью разработки эффективных стратегий повышения конкурентоспособности регионального туризма, в которых бы учитывалась не только общая внешняя экономико-политическая среда, но и внутренние особенности каждого региона. Только при наличии объективных и сопоставимых результатов оценки конкурентоспособности, для регионов Российской Федерации открывается возможность создания необходимых условий для проявления собственных конкурентных преимуществ с целью улучшения своих социально-экономических показателей и престижа на национальном и мировом рынках туристских услуг.

\section{Список используемой литературы}

1. Адельсеитова Э. Б. Обеспечение конкурентоспособности туристской фирмы на основе качества турпродукта / Э. Б. Адельсеитова, Л. Н. Джемилева // Культура народов Причерноморья. -2012 . - № 236 . - С. 10-13.

2. Дмитриев М. Н. Экономика туристского рынка [Электронный ресурс] / М. Н. Дмитриев, М. Н. Забаева, Е. Н. Малыгина. - Режим доступа: http://finlit.online/turizm_760/142konkurentosposobnost-turistskih-4881.html.

3. Мескон М. Основы менеджмента / М. Мескон, М. Альберт, Ф. Хедоури. - М. : Дело, 1993. - $704 \mathrm{c}$.

4. Нездойминов С. Г. Туристский поток - фактор конкурентоспособности региона / С. Г. Нездойминов //Ars Administrandi. - 2014. - № 3. - C. 78-83.

5. Фатхутдинов Р. А. Концепция новой теории управления конкурентоспособностью и конкуренцией / Р. А. Фатхутдинов // Современная конкуренция. -2007 . - № 1. C. $73-86$.

6. Бухер С. Конкурентоспособность России на глобальном туристическом рынке / С. Бухер // Экономика региона. - 2016. — № 1 (12). - С. 240-250.

\section{Baikal Research Journal}

электронный научный журнал Байкальского государственного университета 
7. Солодков М. В. Конкурентоспособность Иркутской области на мировом рынке туристских услуг / М. В. Солодков, А. О. Борисова // Вестник Балтийского федерального университета им. И. Канта. Сер.: Гуманитарные и общественные науки. — 2016. - № 3. C. 95-103.

8. Croitory M. Tourism Competitiveness Index - an empirical analysis of Romania vs. Bulgari / M. Croitory // Theoretical and Applied Economics. - 2011. - № 9 (562). - P. 155-172.

9. Шабалина Н. В. Научное обоснование создания рейтинга развития туризма субъектов РФ [Электронный ресурс] / Н. В. Шабалина // Повышение качества и безопасности услуг объектов туриндустрии как условие успешного продвижения туристского продукта : материалы Междунар. науч.-практ. конф. Сочи, 1-2 дек. 2011 г. - Режим доступа: http:// russiaturforum.com/upload/presentation/117_plenarn_shabalina_sochi.pdf.

10. Воеводина У. Н. Оценка конкурентоспособности развития делового туризма (на примере Псковского региона) / У. Н. Воеводина // Вестник Череповецкого государственного университета. - 2012. - № 1 (1). - С. 27-32.

11. Туменова С. А. Оценка конкурентоспособности рекреационного комплекса региона и стратегические приоритеты (на материалах Кабардино-Балкарской республики) / С. А. Туменова // Известия Кабардино-Балкарского научного центра РАН. - 2009. № 3 (29). — C. 108-116.

12. Narkūnienи R. Eastern Aukљtaitija region tourism competitiveness analysis / R. Narkūnienи // Agricultural Bulletin of Stavropol Region. - 2016. — № 1 (21). - P. 4-8.

13. Флит А. Л. Подходы к определению и оценке факторов конкурентоспособности в индустрии туризма / А. Л. Флит // Вестник Ленинградского государственного университета им. А. С. Пушкина. - 2014. - № 1. - С. 28-37.

14. Dimanche F. Conceptual framework for city tourism competitiveness / F. Dimanche // WTO Forum. New Paradigms for City Tourism Management. Istanbul, Turkey, June 1-3, 2005. - Istanbul, 2005. - P. 273-283.

15. Trisnawati R. Analysis of the competitiveness tourism industries incising the local economy (The comparative study analysis of the competitiveness tourism between Surakarta and Yoguakarta [Electronic resource] / R. Trisnawati // Economic Journal of Emerging Markets. 2008. - № 2 (13). - Mode of access: https://docviewer.yandex.ru/?url=http $\% 3 \mathrm{~A} \% 2 \mathrm{~F} \% 2 \mathrm{~F}$ www.journal.uii.ac.id $\%$ 2Findex.php $\%$ 2FJEP $\%$ 2Farticle $\% 2$ Fdownload $\% 2$ F489 $\%$ 2F403\&nam $\mathrm{e}=403 \&$ lang $=\mathrm{en} \& \mathrm{c}=58 \mathrm{bd} 1 \mathrm{dcb} 2 \mathrm{f} 28 \&$ page $=1$.

\section{References}

1. Adelseitova E. B., Dzhemileva L. N. Providing tourism company's competitiveness on the basis of tourism product quality. Kul'tura narodov Prichernomor'ya = The Culture of the Black Sea Peoples, 2012, no. 236, pp. 10-13. (In Russian).

2. Dmitriyev M. N., Zabayeva M. N., Malygina E. N. Ekonomika turistskogo rynka [Economy of tourism market]. Available at: http://finlit.online/turizm_760/142-konkurentosposobnost-turistskih-4881.html. (In Russian).

3. Mescon M., Albert M., Khedouri F. Management. New York, Harpercollins Publ., 1988. 777 p. (Russ. ed.: Meskon M., Al’bert M., Khedouri F. Osnovy menedzhmenta. Moscow, Delo Publ., 1993. 704 p.).

4. Nezdoiminov S. G. Tourist flow as a factor of regional competitiveness. Ars Administrandi, 2014, no. 3, pp. 78-83. (In Russian).

5. Fatkhutdinov R. A. Concept of new management theory for competitiveness and competition. Sovremennaya konkurentsiya = Journal of Modern Competition, 2007, no. 1, pp. 73-86. (In Russian).

6. Bukher S. Competitiveness of the Russian Federation in the global tourism market. Ekonomika regiona $=$ Regional Economy, 2016, no. 1 (12), pp. 240-250. (In Russian).

7. Solodkov M. V., Borisova A. O. Competitiveness of Irkutsk Oblast in the world tourism market. Vestnik Baltiiskogo federal'nogo universiteta im. I. Kanta. Seriya: Gumanitarnye $i$ obshchestvennye nauki = Bulletin of Immanuel Kant Baltic Federal University. Series: The Humanities and Social Science, 2016, iss. 3, pp. 95-103. (In Russian).

8. Croitory M. Tourism Competitiveness Index - an empirical analysis of Romania vs. Bulgari. Theoretical and Applied Economics, 2011, no. 9 (562), pp. 155-172.

\section{Baikal Research Journal}


9. Shabalina N. V. Scientific background for creating ratting of tourism development in subjects of the Russian Federation. Povyshenie kachestva i bezopasnosti uslug ob"ektov turindustrii kak uslovie uspeshnogo prodvizheniya turistskogo produkta. Materialy mezhdunarodnoi nauchno-prakticheskoi konferentsii. Sochi, 1-2 dekabrya 2011 g. [Improving quality and service security for tourism industry objects as a term of successful promotion of tourism product. Materials of International Research Conference. Sochi, December 1-2, 2011]. Available at: http:// russiaturforum.com/upload/presentation/117_plenarn_shabalina_sochi.pdf. (In Russian).

10. Voyevodina U. N. Assessing competitiveness of developing business tourism (in terms of Pskov Region) Vestnik Cherepovetskogo gosudarstvennogo universiteta = Cherepovets State University Bulletin, 2012, vol. 1, no. 36-1, pp. 27-32. (In Russian).

11. Tumenova S. A. Assessing competitiveness of regional recreation complex and strategic priorities (in terms of Kabardino-Balkar Republic). Izvestiya Kabardino-Balkarskogo nauchnogo tsentra Rossiiskoi akademii nauk = Bulletin of Kabardino-Balkar Scientific Centre of the Russian Academy of Sciences, 2009, no. 3 (29), pp. 108-116. (In Russian).

12. Narkūnienи R. Eastern Aukљtaitija region tourism competitiveness analysis. Agricultural Bulletin of Stavropol Region, 2016, no. 1 (21), pp. 4-8.

13. Flit A. L. Approaches to definition and evaluation of factors of competitiveness in the tourism industry. Vestnik Leningradskogo gosudarstvennogo universiteta im. A. S. Pushkina= Bulletin of Pushkin Leningrad State University, 2014, no. 1, pp. 28-37. (In Russian).

14. Dimanche F. Conceptual framework for city tourism competitiveness. WTO Forum. New Paradigms for City Tourism Management. Istanbul, Turkey, June 1-3, 2005. Istanbul, 2005, pp. 273-283.

15. Trisnawati R. Analysis of the competitiveness tourism industries incising the local economy (The comparative study analysis of the competitiveness tourism between Surakarta and Yoguakarta. Economic Journal of Emerging Markets, 2008, no. 2 (13). Available at: https:// docviewer.yandex.ru/?url=http $\% 3 \mathrm{~A} \% 2 \mathrm{~F} \% 2 \mathrm{Fwww}$.journal.uii.ac.id $\%$ 2Findex.php $\% 2 \mathrm{FJEP} \%$ 2 Farticle $\% 2$ Fdownload $\% 2 F 489 \%$ F403\&name=403\&lang=en\&c=58bd1dcb2f28\&page=1.

\section{Информация об авторе}

Ласси Марина Юрьевна - аспирант, кафедра менеджмента, маркетинга и сервиса, Байкальский государственный университет, 664003, г. Иркутск, ул. Ленина, 11, e-mail: marina_lassi92@mail.ru.

\section{Author}

Marina Yu. Lassi - PhD Student, Chair of Management, Marketing and Services, Baikal State University, 11 Lenin St., 664003, Irkutsk, Russian Federation; e-mail: marina_lassi92@mail.ru.

\section{Библиографическое описание статьи}

Ласси М. Ю. Анализ подходов к оценке конкурентоспособности регионального туризма в России / М. Ю. Ласси // Baikal Research Journal. - 2017. - Т. 8, № 2. - DOI: 10.17150/2411-6262.2017.8(2).24.

\section{Reference to article}

Lassi M. Yu. Analysis of approaches to assessing competitiveness of regional tourism in Russia. Baikal Research Journal, 2017, vol. 8, no. 2. DOI: 10.17150/2411-6262.2017.8(2).24. (In Russian).

\section{Baikal Research Journal}

